Penerbit:

Program Studi Magister Ilmu Kesehatan Masyarakat, Program Pascasarjana, Universitas Sam Ratulangi

Indonesian Journal of Public Health and Community Medicine is indexed by Google Scholar and licensed under a Creative Commons Attribution 4.0 International License.

\title{
Faktor-Faktor Yang Berhubungan Dengan Pemberian ASI Eksklusif
}

\author{
${ }^{1}$ Oktavin Yollah Umboh*, ${ }^{2}$ Adrian Umboh, ${ }^{2}$ David Kaunang
}

\author{
${ }^{1}$ Program Studi Ilmu Kesehatan Masyarakat Program Pascasarjana Universitas Sam Ratulangi \\ ${ }^{2}$ Program Studi Ilmu Kesehatan Anak Fakultas Kedokteran Universitas Sam Ratulangi \\ E-mail: oktavin.yollah@gmail.com
}

\begin{abstract}
Abstrak
Latar Belakang: Pemberian ASI tanpa bahan makanan lain dapat mencukupi kebutuhan pertumbuhan bayi sampai berusia enam bulan. Capaian pemberian ASI eksklusif di Indonesia belum memuaskan. Tujuan penelitian ini yaitu untuk menganalisis faktor-faktor yang berhubungan dengan pemberian ASI eksklusif di Wilayah Kerja Puskesmas Teling Kota Manado. Metode Penelitian: Penelitian ini merupakan penelitian kuantitatif dengan metode survey analitik dan pendekatan cross sectional pada bulan November 2018 sampai dengan Maret 2019 di Wilayah Kerja Puskesmas Teling Atas Kota Manado terhadap 140 orang ibu sebagai sampel. Variabel penelitian diukur dengan menggunakan kuisioner selanjutnya dianalisis menggunakan uji chi square dan regresi berganda. Hasil Penelitian: Hasil penelitian didapati adanya hubungan signifikan antara pekerjaan ibu $(p=0,006)$ dengan pemberian ASI eksklusif sedangkan pendidikan ibu, pengetahuan ibu, dukungan keluarga dan motivasi tenaga kesehatan tidak memiliki hubungan yang bermakna dengan pemberian ASI eksklusif (p>0,05). Hasil analisis multivariat menunjukkan bahwa pengetahuan ibu sangat mempengaruhi pemberian ASI eksklusif ( $p=0,04$ dan $O R=2,531)$. Kesimpulan: Kesimpulan penelitian ini yaitu faktor pekerjaan ibu memiliki hubungan signifikan dengan pemberian ASI eksklusif dan faktor lainnya tidak berhubungan. Selanjutnya, faktor yang paling berpengaruh dengan pemberian ASI eksklusif yaitu pengetahuan ibu. Oleh karena itu, petugas kesehatan di Puskesmas lebih aktif memberikan motivasi kepada ibu hamil dan menyusui tentang manfaat dan cara pemberian ASI eksklusif.

Kata Kunci: ASI eksklusif; puskesmas Teling
\end{abstract}

\section{Abstract}

Background: Breastfeeding without other food can meet the growing needs of a baby up to six months of age. The achievement of exclusive breastfeeding in Indonesia has not satisfactory. The purpose of this study was to determine the factors correlated with exclusive breastfeeding. Methode: This research is a quantitative study using an analytical survey method and a cross sectional approach from November 2018 to March 2019 in the Teling Atas Community Health Center in Manado, involving 140 mothers as a sample. The research variables were measured using a questionnaire and then analyzed using chi square and multiple regression test. Result: This study showed that there was a significant relationship between maternal occupation (p 0,006) and exclusive breastfeeding, while maternal education, maternal knowledge, family support and motivation of health workers had no significant relationship with exclusive breastfeeding $(p>0,05)$. The results of multivariate analysis showed that maternal knowledge greatly influenced exclusive breastfeeding (p 0.04 and OR 2.531). Conclusion: The conclusion 
of this study is that the maternal occupational factors had a significant correlation with exclusive breastfeeding. However, the community health center should be more active in motivating pregnant and breastfeeding mother about the benefits and methods of exclusive breastfeeding. Key words: exclusive breastfeeding; Teling community health center

\section{PENDAHULUAN}

Air Susu Ibu (ASI) merupakan nutrisi terbaik untuk bayi dan merupakan awal yang baik dalam menyiapkan sumber daya manusia suatu bangsa dalam menyongsong masa depan. Selaisn itu, ASI juga memiliki peran penting dalam menjaga kesehatan, mempertahankan kelangsungan hidup bayi, serta berdampak positif terhadap tumbuh kembang anak karena nutrisi yang terkandung dalam ASI dapat memenuhi kebutuhan nutrisi yang diperlukan anak pada masa pertumbuhannya. Pemberian ASI tanpa bahan makanan lain dapat mencukupi kebutuhan pertumbuhan bayi sampai berusia enam bulan. Setelah bayi berusia enam bulan diberikan tambahan makanan pendamping ASI (MPASI) dan pemberian ASI dilanjutkan sampai dengan usia dua tahun (Infodatin, 2017).

Data Badan Kesehatan Dunia menyatakan bahwa hanya $41 \%$ bayi yang memperoleh ASI eksklusif. Capaian ASI eksklusif di Indonesia sesuai hasil pemantauan status gizi tahun 2017 sebesar 35,7 \% (Kemenkes RI, 2018). Pemberian ASI eksklusif pada bayi berusia 0 - 6 bulan di Kota Manado tahun 2017 hanya diberikan pada 1.820 bayi ( $25,8 \%$ ) dari 7.054 total bayi usia $0-6$ bulan. Capaian ini masih jauh dari target yang diharapkan yaitu sebesar 80 \% (WHO, 2018; Dinkes Kota Manado, 2017)

Sudargo et al (2018) menyatakan bahwa faktor-faktor yang berhubungan dengan pemberian ASI eksklusif, yaitu faktor pendidikan, faktor ekonomi, faktor pengetahuan, faktor dukungan dari keluarga, faktor sosial budaya dan kondisi khusus yang memaksa untuk memberikan makanan selain ASI kepada bayi tanpa ada pilihan lain, misalnya ibu meninggal, ASI tidak keluar sama sekali. Penelitian dari Kurniawan (2013) menyimpulkan bahwa terdapat hubungan signifikan antara pekerjaan ibu dengan pemberian ASI eksklusif dimana pada ibu yang bekerja, persentase pemberian ASI eksklusif lebih kecil dibandingkan dengan ibu yang tidak bekerja. Penelitian Astuti (2013) menemukan adanya hubungan pendidikan ibu, pengetahuan ibu, pekerjaan ibu, peran petugas kesehatan, keterpaparan media informasi, peran suami dan peran orang tua dengan pemberian ASI eksklusif.

Berdasarkan laporan program gizi tahun 2017 dari Puskesmas Teling Atas Kota Manado ditemukan bahwa pemberian ASI eksklusif di wilayah kerja puskesmas hanya sebesar 23,4 \% dari 167 sasaran bayi yang berusia $0-6$ bulan. Cakupan ini masih jauh dari target yaitu $80 \%$. Oleh karena itu, penulis tertarik untuk melakukan penelitian untuk menganalisis faktor-faktor yang menyebabkan rendahnya cakupan pemberian ASI eksklusif ini. Tujuan penelitian ini yaitu untuk menganalisis faktor-faktor yang berhubungan dengan pemberian ASI eksklusif di wilayah kerja Puskesmas Teling Atas Kota Manado.

\section{METODE PENELITIAN}

Penelitian ini merupakan penelitian kuantitatif dengan metode survey analitik dan pendekatan cross-sectional. Penelitian ini dilakukan pada bulan November 2018 sampai dengan Maret 2019 di Wilayah Kerja Puskesmas Teling Atas Kota Manado. Jumlah responden dalam penelitian ini yaitu 140 orang ibu yang memenuhi syarat yaitu memiliki anak yang berusia $0-6$ bulan, tidak memiliki penyakit/ kelainan yang bisa mempengaruhi pemberian ASI eksklusif dan bersedia menjadi responden penelitian. Variabel penelitian 
yaitu pendidikan ibu, pekerjaan ibu, pengetahuan ibu, dukungan keluarga, motivasi tenaga kesehatan dan pemberian ASI ekslusif. Variabel ini diukur dengan menggunakan kuisioner. Analisis data dilakukan secara univariat dan bivariat. Secara univariat dilakukan penjelasan tentang karakteristik dan variabel penelitian berdasarkan jumlah dan persentase. Analisis bivariat dilakukan untuk menganalisis variabel yang berhubungan dengan pemberian ASI eksklusif. Analisis ini menggunakan uji khi kuadrat.

\section{HASIL DAN PEMBAHASAN}

Distribusi responden berdasarkan pendidikan ibu, pekerjaan ibu, pengetahuan ibu, dukungan keluarga, motivasi tenaga kesehatan dan pemberian ASI eksklusif serta hasil analisis khi kuadrat dapat dilihat pada Tabel 1.

Tabel 1. Hasil analisis data

\begin{tabular}{|c|c|c|c|c|c|c|c|}
\hline \multirow{3}{*}{ Variabel } & \multicolumn{4}{|c|}{ Riwayat Pemberian ASI } & & & \multirow{3}{*}{$\mathrm{p}$ value } \\
\hline & \multicolumn{2}{|c|}{ ASI Eksklusif } & \multicolumn{2}{|c|}{$\begin{array}{c}\text { Tidak } \\
\text { ASI Eksklusif }\end{array}$} & \multicolumn{2}{|c|}{ Total } & \\
\hline & $\mathrm{N}$ & $\%$ & $\mathrm{n}$ & $\%$ & $\mathrm{n}$ & $\%$ & \\
\hline \multicolumn{8}{|l|}{ Pendidikan Ibu } \\
\hline Tinggi & 13 & 23,2 & 43 & 76,8 & 56 & 100 & \multirow{2}{*}{0,317} \\
\hline Dasar/Menengah & 26 & 31 & 58 & 69 & 84 & 100 & \\
\hline \multicolumn{8}{|l|}{ Pekerjaan Ibu } \\
\hline Bekerja & 8 & 14,8 & 46 & 85,2 & 54 & 100 & \multirow{2}{*}{0,006} \\
\hline Tidak Bekerja & 31 & 36 & 55 & 64 & 86 & 100 & \\
\hline \multicolumn{8}{|l|}{ Pengetahuan Ibu } \\
\hline Baik & 30 & 33 & 61 & 67 & 91 & 100 & \multirow{2}{*}{0,066} \\
\hline Kurang Baik & 9 & 18,4 & 40 & 81,6 & 49 & 100 & \\
\hline \multicolumn{8}{|l|}{ Dukungan Keluarga } \\
\hline Mendukung & 34 & 30,9 & 76 & 69,1 & 110 & 100 & \multirow{2}{*}{0,123} \\
\hline Tidak Mendukung & 5 & 16,7 & 25 & 83,3 & 30 & 100 & \\
\hline \multicolumn{8}{|l|}{$\begin{array}{c}\text { Motivasi Tenaga } \\
\text { Kesehatan }\end{array}$} \\
\hline Tinggi & 28 & 26,9 & 76 & 73,1 & 104 & 100 & \multirow{2}{*}{0,675} \\
\hline Rendah & 11 & 30,6 & 25 & 69,4 & 36 & 100 & \\
\hline
\end{tabular}

Tabel 1 menunjukkan bahwa sebagian besar responden berpendidikan terakhir sekolah dasar/menengah (60\%), tidak bekerja (61\%), berpengetahuan baik (65\%), keluarga mendukung pemberian ASI eksklusif $(78,6 \%)$, motivasi tenaga kesehatan yang tinggi $(74,3 \%)$ dan tidak memberikan ASI eksklusif $(72,1 \%)$. Selanjutnya dilakukan analisis bivariat untuk melihat hubungan antara pendidikan ibu, pekerjaan ibu, pengetahuan ibu, dukungan keluarga dan motivasi tenaga kesehatan dengan pemberian ASI.

Data pada tabel 1 menunjukkan bahwa dari 84 responden yang berpendidikan dasar/menengah, 58 responden (69\%) tidak memberikan ASI eksklusif dan 26 responden (31\%) yang memberikan ASI eksklusif. Responden yang berpendidikan tinggi berjumlah 56 responden dimana 43 responden $(76,8 \%)$ tidak memberikan ASI eksklusif. Hasil uji chi square menunjukkan bahwa tidak ada hubungan signifikan pendidikan ibu dengan 
pemberian ASI eksklusif $(\mathrm{p}=0,317)$. Hasil Penelitian ini sejalan dengan penelitian yang dilakukan oleh Rahmawati et al (2013) dimana tidak terdapat hubungan signifikan antara pendidikan ibu dengan pemberian ASI eksklusif di wilayah kerja Puskesmas Bonto Cani Kabupaten Bone $(p=0,211)$. Tingkat pendidikan ibu yang tinggi belum tentu mempengaruhi ibu dalam memberikan ASI eksklusif.

Hasil penelitian menunjukkan bahwa sebagian besar responden tidak bekerja ( 86 responden). Dari 86 Responden yang tidak bekerja, 55 responden (64\%) tidak memberikan ASI eksklusif sedangkan 31 responden (36\%) memberikan ASI eksklusif kepada anaknya. Ibu yang bekerja sebanyak 54 responden dimana 46 responden $(85,2 \%)$ tidak memberikan ASI eksklusif dan hanya 8 responden $(14,8 \%)$ yang memberikan ASI eksklusif. Berdasarkan hasil uji chi square menunjukkan bahwa ada hubungan yang signifikan antara pekerjaan ibu dengan pemberian ASI eksklusif $(\mathrm{p}=0,006)$. Timporok et al (2018) pada penelitian yang di Wilayah Kerja Puskesmas Kawangkoan juga memperoleh hasil yang sama dimana terdapat hubungan signifikan antara pekerjaan ibu dengan pemberian ASI eksklusif ( $\mathrm{p}=0,000)$. Damayanti et al (2020) pada penelitiannya di wilayah kerja Puskesmas Werdhi Agung Kecamatan Dumoga Tengah juga mendapatkan adanya hubungan signifikan antara pekerjaan. Pekerjaan mempengaruhi ibu untuk memberikan ASI secara eksklusif. Hal ini dikarenakan kesibukan ibu sehingga tidak cukup untuk memperhatikan kebutuhan ASI bayinya. Dukungan dari tempat kerja sangat diperlukan agar ibu dapat memberikan ASI eksklusif kepada bayinya. Peraturan Pemerintah No. 33 tahun 2012 tentang Pemberian ASI Eksklusif pasal 30 mengatakan bahwa instansi kerja dan sarana umum seharusnya memberikan dukungan terhadap program ASI eksklusif dan bisa mengatur hubungan kerja antara perusahaan dengan karyawan. Penanggung jawab instansi dan penyelenggara tempat umum harus memfasilitasi perempuan yang dalam masa menyusui untuk tetap memberikan ASInya baik itu dengan menyusui di tempat kerja pada ruangan khusus atau hanya sekedar untuk memerah ASI.

Selanjutnya berdasarkan pengetahuan ibu, ditemukan bahwa pada 91 responden memiliki pengetahuan yang baik dan 61 responden $(67 \%)$ tidak memberikan ASI eksklusif sedangkan responden yang memberikan ASI eksklusif berjumlah 30 responden (33\%). Responden yang memiliki pengetahuan kurang baik, hanya 9 responden $(18,4 \%)$ yang memberikan ASI eksklusif sedangkan 40 responden $(81,6 \%)$ tidak memberikan ASI eksklusif. Hasil uji chi square menunjukkan bahwa tidak ada hubungan yang signifikan antara pengetahuan ibu dengan pemberian ASI eksklusif $(\mathrm{p}=0,066)$. Penelitian ini sejalan dengan penelitian yang dilakukan Ramli (2020) di kelurahan Sidotopo, Jawa Timur dimana tidak terdapat hubungan signifikan anatara pengetahuan ibu dengan pemberian ASI eksklusif ( $\mathrm{p}=0,346)$. Penelitian tentang ASI eksklusif yang dilakukan di Puskesmas Bahu Kecamatan Malalayang oleh Mabud et al (2014) mendapatkan hasil bahwa sebagian besar ibu memiliki tingkat pengetahuan yang baik, tetapi tidak seluruhnya menyusui bayinya secara eksklusif.

Data pada tabel 1 menunjukkan bahwa terdapat 110 responden mendapat dukungan keluarga dalam pemberian ASI eksklusif. Dimana 76 responden $(69,1 \%)$ tidak memberikan ASI eksklusif sedangkan 34 responden (30,9\%) memberikan ASI eksklusif. Ibu yang keluarganya tidak mendukung sebanyak 30 responden dimana 25 responden $(83,3 \%)$ tidak memberikan ASI eksklusif dan 5 responden $(16,7 \%)$ memberikan ASI eksklusif. Hasil uji chi square menunjukkan tidak ada hubungan yang signifikan antara dukungan keluarga dengan pemberian ASI eksklusif $(p=0,123)$. Penelitian ini sejalan dengan penelitian yang dilakukan Abdullah dan Ayubi (2013) pada ibu pekerja di 
Kementerian Kesehatan, dimana tidak terdapat hubungan signifikan antara dukungan suami terhadap pemberian ASI eksklusif. Hasil yang berbeda didapatkan oleh Tulangow et al (2019) dimana terdapat hubungan signifikan antara dukungan keluarga dengan pemberian ASI eksklusif pada ibu pekerja di wilayah kerja Puskesmas Sagerat Kecamatan Matuari Kota Bitung.

Hasil penelitian ini menunjukkan bahwa sebanyak 104 responden mendapatkan motivasi yang tinggi dari tenaga kesehatan dari 104 responden tersebut, 76 responden $(73,1 \%)$ tidak memberikan ASI eksklusif sedangkan 28 responden $(26,9 \%)$ memberikan ASI eksklusif. Ibu yang mendapatkan motivasi rendah dari tenaga kesehatan sebanyak 36 responden, dimana 25 responden $(69,4 \%)$ tidak memberikan ASI eksklusif dan 11 responden $(30,6 \%)$ yang memberikan ASI eksklusif. Hasil uji khi kudrat menunjukkan bahwa tidak ada hubungan yang bermakna antara motivasi tenaga kesehatan dengan pemberian ASI eksklusif $(\mathrm{p}=0,675)$. Penelitian ini berbeda dengan hasil penelitian Widdefrita dan Mohanis (2013) dimana terdapat hubungan signifikan antara peran petugas kesehatan dengan pemberian ASI eksklusif.

\section{PENUTUP}

Kesimpulan penelitian ini menunjukkan bahwa faktor pekerjaan ibu merupakan faktor yang menentukan pemberian ASI eksklusif dimana ibu yang bekerja lebih rendah untuk memberikan ASI eksklusif. Oleh karena itu, perlu dibuat suatu regulasi yang memudahkan ibu memberikan ASI eksklusif bagi ibu yang bekerja seperti menyiapkan ruangan ASI di setiap tempat kerja dan fasilitas umum/ pusat perbelanjaan.

\section{REFERENSI}

Abdullah, G. dan D. Ayubi. 2013. Determinan Perilaku Pemberian Air Susu Ibu Eksklusif Pada Ibu Pekerja. Jurnal Kesehatan Masyarakat Nasional .Vol. 7, No. 7 Hal. $298-303$.

Astuti, I. 2013. Determinan pemberian ASI eksklusif pada ibu menyusui. Jurnal Health Quality, 4(1), 1-76.

Damayanti, N. A., Doda, V., \& Rompas, S. (2020). Status Gizi, Umur, Pekerjaan Dengan Pemberian Asi Eksklusif Pada Bayi Usia 6-12 Bulan Saat Ibu Kembali Bekerja. Jurnal Keperawatan, 8(1), 23-32.

Dinas Kesehatan Kota Manado. 2017. Profil Dinas Kesehatan Kota Manado 2017. Manado.

Infodatin. 2017. Mari Dukung Menyusui Dan Bekerja. Pusat Data Dan Informasi Kementerian Kesehatan. (online) diakses dari www.depkes.go.id pada 7 Januari 2021

Kemenkes RI. 2018. Buku Saku Pemantauan Status Gizi Tahun 2017 (online) diakses dari www.kesmas.kemkes.go.id pada 7 Januari 2021.

Kurniawan, B. 2013. Determinan keberhasilan pemberian air susu ibu eksklusif. Jurnal Kedokteran Brawijaya, 27(4), 236-240.

Mabud, N. H., J. Mandang dan T. Mamuaya. 2014. Hubungan Pengetahuan, Pendidikan, Paritas dengan Pemberian ASI Eksklusif di Puskesmas Bahu Kecamatan Malalayang Kota manado. Jurnal Ilmiah Bidan. Volume 2 Halaman 51 - 56.

Rahmawati, A., B. Bahar dan A. Salam. 2013. Hubungan Antara Karakteristik Ibu, Peran Petugas Kesehatan dan Dukungan Keluarga dengan Pemberian ASI Eksklusif di Wilayah Kerja Puskesmas Bonto Cani Kabupaten Bone. Jurnal Kesehatan. Vol. $2: 31-39$ 
Ramli, R. 2018. Hubungan Pengetahuan dan Status Pekerjaan Ibu dengan Pemberian ASI Eksklusif di Kelurahan Sidotopo. Jurnal Promkes: The Indonesian Journal of Health Promotion and Health Education. Vol. 8 No. 1 Hal. 36 - 46.

Sudargo, T., T. Aristasari dan A. Afifah. 2018. 1.000 Hari Pertama Kehidupan. Cetakan I. Gadjah Mada University Press. Yogyakarta. $221 \mathrm{Hal.}$

Timporok, A. G. A., P. M. Wowor dan S. Rompas. 2018. Hubungan Status Pekerjaan Ibu Dengan Pemberian ASI Eksklusif Di Wilayah Kerja Puskesmas Kawangkoan. e-Journal Keperawatan (eKp). Vol. 6 No. 1, Hal 1-6.

Tulangow, C. V., D. V. Doda dan J. A. M. Rattu. 2019. Hubungan Antara Beban Kerja, Stres Kerja Dan Dukungan Keluarga Dengan Pemberian ASI Eksklusif Oleh Ibu Pekerja Di Wilayah Kerja Puskesmas Sagerat Kecamatan Matuari Kota Bitung. Paradigma Sehat, Vol. 7 No. 1, Hal 62-69.

World Health Organization. 2018. World Breasfeeding Week 2018 (online) diakses dari www.who.int/news-room/events/2018 pada 7 Januari 2021.

Widdefrita dan Mohanis. 2013. Peran Petugas Kesehatan Dan Status Pekerjaan Ibu Dengan Pemberian ASI Eksklusif. Jurnal Kesehatan Masyarakat, Vol. 8, No. 1, Hal 40-45. 